\title{
Pediatric Crohn's disease: epidemiology and emerging treatment options
}

This article was published in the following Dove Press journal:

Pediatric Health, Medicine and Therapeutics

5 July 2014

Number of times this article has been viewed

\author{
Shivani Kansal ${ }^{1-3}$ \\ Anthony G Catto-Smith ${ }^{1,2}$ \\ 'Department of Paediatrics, University \\ of Melbourne, ${ }^{2}$ Department of \\ Gastroenterology, The Royal \\ Children's Hospital Melbourne, \\ 3Murdoch Children's Research \\ Institute, Melbourne, VIC, Australia
}

\begin{abstract}
There has been a dramatic increase in the incidence of Crohn's disease over the last two to three decades worldwide, which has affected both the developed world and increasingly also the developing world. Crohn's disease is a disease of youth and can have a profound effect on the growing child, both in terms of growth and skeletal health as well psychosocial maturation. Environmental risk factors appear to be crucially important, but it is not clear at present whether improved hygiene, especially in childhood, influences immunological conditioning, or whether there is a direct impact on the gut from a disturbed gut microbiota. Genetic variation appears to relate to how the host interacts with its microbiota, determining susceptibility rather than causation. The outcome is a sustained immune response, clinically presenting as a relapsing/ remitting disease process. There is no current cure for Crohn's disease; treatments are designed to reduce symptoms and control inflammation, initially by inducing a remission, then trying to maintain it. Historical therapies have included 5-aminosalicylic acid-based drugs, corticosteroids, and immunomodulators. Two approaches which are gaining increasing interest are the use of exclusive enteral nutrition and biologicals. Enteral nutrition is a remarkably effective approach, though there is a limited understanding of its mechanism and difficulties in acceptance among the medical community. Biologicals are a class of drugs which specifically target molecules and pathways central to the inflammatory process; they are also very effective, but patients can develop a secondary loss of response as a result of antibodies to the biological agent. Infection and the development of secondary malignancies have provided concerns with these very potent agents and with combination therapies, but inadequately controlled disease appears to pose a bigger threat for many patients than the side effects of medications. A wide range of alternative therapies are also being explored, such as the manipulation of gut flora and pathways which might influence immune responsiveness. The marked recent increase in Crohn's disease, especially in children, has prompted a large research effort which to date has led to a better knowledge of the biology of the disease and more effective treatments. These therapies need to be used judiciously to optimize benefit and minimize side effects.
\end{abstract}

Keywords: inflammatory bowel disease, ulcerative colitis, tumor necrosis factor, biologicals, microbiota, enteral nutrition

\section{Introduction}

Crohn's disease and ulcerative colitis are chronic inflammatory conditions affecting the gastrointestinal tract which are associated with substantial morbidity. Up until two to three decades ago they were relatively rare in children, but in recent years they have become increasingly more common. This change in incidence has been associated with substantial improvements in therapeutic options, although a cure is not yet available for either condition. The lifelong relapsing-remitting nature of these conditions has 
the potential for impacting growth, development, and quality of life.

This review will focus particularly on Crohn's disease, with discussion of its changing epidemiology, emerging treatment options, and its impact in children.

\section{Epidemiology}

Crohn's disease was first described as a clinical entity by Burrill B Crohn and colleagues in the USA in $1932^{1}$ and has traditionally been regarded as a disease of the Western world. A rising incidence in both adults and children has been observed in recent years, ${ }^{2-5}$ with some studies suggesting a ten-fold to 20 -fold increase in children over three decades. ${ }^{2}$ Crohn's disease currently affects about 700,000 people in the USA and about a million people in Europe. ${ }^{3,6}$ The annual all-age incidence rate from Australia is now of the order of 17 per 100,000 per year. ${ }^{7}$ However, it is now also being increasingly recognized in the more affluent areas of Asia, Eastern Europe, and South America. ${ }^{3}$ The situation in the developing world is not clear, as population-based data on the incidence and prevalence is generally lacking. ${ }^{3}$ This may in part explain the apparently disproportionately high incidence further from the equator in more developed countries, which are likely to have better population data. Not surprisingly, there is evidence that access to medical services may influence the reported incidence of inflammatory bowel disease (IBD). One study from the Punjab in North India was only able to be carried out by utilizing a house-to-house search with gastrointestinal endoscopy carried out on suspected cases. ${ }^{8}$

Nevertheless, there is some evidence that environmental risk factors are important, especially those present during childhood. ${ }^{9}$ Crohn's disease occurs more commonly in urban versus rural regions. ${ }^{2,10,11}$ Improved hygiene, especially in childhood, is thought to be an important risk factor. ${ }^{10,12}$ Migration from areas of low incidence to high incidence countries increases risk to that present in the population of the adoptive country, ${ }^{13}$ but age is of pivotal importance. This increased risk is only present for those who migrate during childhood, not as adults. ${ }^{13}$ Early life events, the environment, or immunological conditioning appear to be crucial determinants in the later development of IBD, emphasizing both the importance of childhood studies and the primacy of environment over genetic susceptibility.

Crohn's disease is likely to occur equally among the sexes, as reported sex differences are largely inconsistent. Although Crohn's disease can present at almost any age, it is most likely to present between the second and fourth decades of life. ${ }^{3}$
Fifteen percent to $25 \%$ of patients with Crohn's disease present in childhood. ${ }^{3}$ The incidence of Crohn's disease during childhood has been reported to range between 2.2 to 6.8 per 100,000 children aged $0-16$ years, ${ }^{5}$ but there are marked variations between different parts of the world. There has been a dramatic increase in pediatric Crohn's disease in Australia over the last three to four decades (Figure 1), with the current standardized incidence rate being greater than 2.0 per 100,000 children aged 16 years or younger. ${ }^{2}$ While the peak age of new diagnosis for Crohn's disease overall is between the second and fourth decades, the average age in pediatric practice is about 11 years $^{2}$ (Figure 2). A study from Scotland reported a doubling of the incidence of pediatric Crohn's disease over the 15-year period to 1995 , with an overall averaged standardized incidence rate of 2.5 cases per 100,000 population for the period. ${ }^{14}$ Marked increases in pediatric diagnoses have also been confirmed in other parts of Europe, such as Sweden, Czechoslovakia, and the UK, while elsewhere, such as Canada and the USA, they appear to have plateaued after previously documented increases. ${ }^{5}$

What is clear is that the trend is for an increase in most parts of the world, and now particularly in areas that were previously of very low incidence. Twenty years ago, IBD was almost unknown in the People's Republic of China. Recently, a multicenter, retrospective audit of over a decade of experience with childhood IBD from 2000-2010 in Shanghai has shown a steadily increasing trend in children aged 0-14 years. ${ }^{15}$ The peak prevalence was in children aged 10-14 years. $\mathrm{Ng}$ et $\mathrm{al}^{16}$ compared regions within the Asia Pacific of newly increased incidence with others of established high incidence, such as Australia, for affected adults. While the incidence of IBD was still less in Asia than that of Australia, the numbers involved were still substantial. Southeast Asia had an incidence rate varying from $0.15-1.0$ per 100,000 individuals. The People's Republic of China had the highest

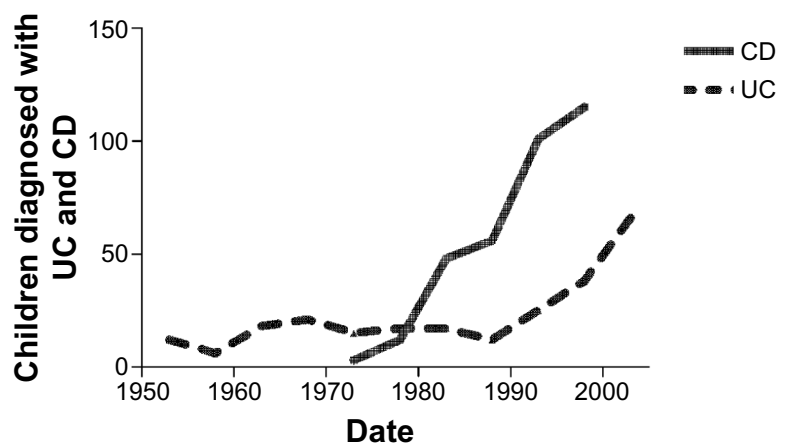

Figure I Historical trends in numbers of children diagnosed with UC and CD in Victoria, Australia.

Notes: Data trends presented in 5-year epochs. Data taken from Phavichitr et al ${ }^{2}$ and Schildkraut et al. ${ }^{162}$

Abbreviations: CD, Crohn's disease; UC, ulcerative colitis. 




Figure 2 Age at diagnosis for children diagnosed with Crohn's disease in Victoria, Australia.

Notes: Data taken from Phavichitr et al. ${ }^{2}$ The apparent reduction in numbers of children diagnosed at age 16 is likely related to a proportion of these children being identified through adult physicians and thus not identified through children's hospital datasets.

adult incidence rate of IBD in Asia, with 3.4 per 100,000 individuals. Clinical phenotype was nevertheless similar to that seen in the West.

While both ulcerative colitis and Crohn's disease are increasing in incidence, there is some evidence that Crohn's disease is becoming the predominant form of IBD in developed countries, although there is also evidence of an increase in ulcerative colitis as well. ${ }^{13}$ IBD has a low mortality, and as the disease is most diagnosed in the young, this is likely to lead to a substantial growth in the global numbers of affected individuals. ${ }^{3}$

\section{Epidemiology and etiology}

Any discussion of the epidemiology of Crohn's disease requires a summary of current theories of causation. The exact etiology of Crohn's disease remains unknown. It appears to represent a sustained immune response, clinically presenting as a relapsing/ remitting disease process. It is currently believed that Crohn's disease occurs as part of an interplay between environmental and immunological factors in a genetically susceptible host. Epidemiological studies which have shown a rapid increase in incidence and studies that have shown strong environmental influences point to the environment as being key. These changes have come too quickly to represent any change in the gene pool. ${ }^{13}$ Nevertheless, genetic studies have provided intriguing information. One of the most interesting conclusions is that genetic susceptibility for Crohn's disease is defined by variations in how the host interacts with its microbiota. ${ }^{17}$ These have been recognized as alterations in epithelial barrier function, and at the level of innate and adaptive immunity to the microbiota. ${ }^{13}$ It appears to be the host's relationship to its own microbial environment that is the key trigger for Crohn's disease in particular.

The first gene implicated in susceptibility to Crohn's disease was the nucleotide-binding oligomerization domain- containing protein 2 (NOD2) gene, also called caspase recruitment domain-containing protein 15 or inflammatory bowel disease protein $1 .^{18}$ It is located on chromosome 16, recognizes bacterial muramyl dipeptide, and regulates immune response to bacteria. ${ }^{19,20}$ Loss of function variants of the NOD2 gene have been associated with increased susceptibility to Crohn's disease, especially small bowel disease. ${ }^{18,21-23}$ Other loci involved with increased susceptibility to Crohn's disease include IBD5,3,6 on chromosomes 5, 6 , and 19 , respectively. ${ }^{20,24}$

Another genetically defined process which can contribute to susceptibility to Crohn's disease is that of autophagy. Autophagy is a process that mediates degradation of intracellular proteins via vesicle-mediated delivery to lysosomes. Defects in autophagy could potentially alter the immune responsiveness to intracellular pathogens. Autophagy is believed to be mediated through at least three component genes - ATG16L1, IRGM, and NOD2. ${ }^{22}$ ATG16L1 is essential for autophagy, and the coding mutation T300A is associated with an increased risk of Crohn's disease. ${ }^{22}$

The search for a microbial trigger for Crohn's disease has been carried out along two pathways - either a specific transmissible agent, or a dysbiosis involving the gastrointestinal microbial milieu. Dysbiosis refers to the breakdown of balance between commensal bacteria and harmful bacteria in the gut. ${ }^{25}$ The gut microbiota is relatively difficult to characterize, and the functional implications of differing populations and their interactions are not really understood. ${ }^{26}$ Recent advances in metagenomics have certainly strongly supported the presence of a dysbiosis in patients with Crohn's disease. ${ }^{25}$ One of the most interesting observations, however, is that Crohn's disease is associated with markedly reduced bacterial diversity. ${ }^{27}$ Whether this is a cause or effect of inflammation is unknown.

Although most interest has focused on bacterial populations, some attention has been provided to other members of the gut microbiota, such as viruses. ${ }^{28}$ There is little evidence at present to support them as specific transmissible agents, ${ }^{28}$ but an area that is starting to be explored is that of bacterial viruses, or bacteriophages. ${ }^{29}$ The introduction of nextgeneration sequencing has transformed our ability to define bacteriophages, which represent the most genetically diverse components in the biosphere. ${ }^{30}$ Bacteriophages themselves are extremely numerous, and are reported to be the most abundant replicating entities on the planet. ${ }^{31}$ They are likely to impact gut function via their impact on bacterial metabolism, interactions, pathogenicity, and diversity. ${ }^{31}$

The other major thrust of research has been into a specific transmissible agent. Although a number have been proposed, 
one which has received the most enduring interest and also been the most controversial has been Mycobacterium avium subspecies paratuberculosis. ${ }^{32}$ This has been identified in up to half of newly diagnosed children. ${ }^{33}$ The infection is widely disseminated in cattle populations and is the cause of bovine bowel disease, which has many similarities to Crohn's disease in humans; there is also evidence that it has been increasing in cattle herds. ${ }^{13}$ The controversial aspect is whether or not it might be of etiological importance in human disease. ${ }^{34}$ The economic implications were this to be confirmed would be very substantial, but strong circumstantial evidence continues to emerge. ${ }^{35,36}$

The hygiene hypothesis has been an attempt to synthesize this complex interplay between genetically defined immunological susceptibility factors and the microbiome. ${ }^{10}$ This postulates that multiple childhood exposures to enteric pathogens and immunological stimuli protect an individual from developing Crohn's disease later in life, while individuals raised in a more sanitary environment are more likely to develop Crohn's disease.

\section{Current and emerging treatment options}

In the absence of a deeper understanding of the pathogenesis of Crohn's disease, treatments are for the most part directed at influencing inflammation. A cure is not possible, and therapeutic interventions are designed to relieve symptoms, improve the quality of life, and avert long-term complications. Historically, medications have been employed either to induce or to maintain a remission. Step-up therapy has been the traditional approach, using, for instance, aminosalicylates, then topical steroids, then systemic steroids, and going to immunosuppression or potent new biological agents if necessary. ${ }^{37}$ Clinical symptoms have by and large driven each step. Unfortunately, the natural history of Crohn's disease is marked by recurrent acute flares and progressive bowel wall damage. ${ }^{37}$ This has led to the concept of top-down treatment with prevention of structural damage by achieving mucosal healing, necessitating more aggressive treatment with earlier use of immunosuppressants and biologicals together with closer surveillance of mucosal inflammation, whether by endoscopy or by indirect fecal markers of gut inflammation.

It is widely believed that this top-down approach helps to modify the natural course of the disease. ${ }^{38}$ Studies have also shown that early introduction of immunomodulators has a steroid-sparing effect and improved maintenance of remission. ${ }^{39}$ Top-down therapy has been associated with reduced rates of surgery and hospitalizations, but the concern has been for the increased risk of infections associated with immunosuppressants together with the cost of agents such as biologicals. Under-treatment and over-treatment are both to be avoided, and there is increasing interest in tailoring therapy to the individual's needs - personalized medicine. ${ }^{40,41}$ One aspiration is that defining genetic susceptibility patterns may help guide treatments on an individual basis. ${ }^{41}$

\section{5-ASA-based preparations}

Preparations of 5-aminosalicylic acid (5-ASA) are frequently the first-line management in patients with mild Crohn's disease, particularly when it involves the colon. Sulfasalazine is a combination of 5-ASA and sulfapyridine which acts as a carrier to the colon. ${ }^{42}$ In the colon, the sulfasalazine is broken down into 5-ASA and sulfapyridine by azoreductase enzymatic activity from colonic bacteria. ${ }^{43} 5$-ASA is the active moiety. Randomized controlled trials have shown sulfasalazine to be better than placebo in inducing remission in active colonic Crohn's disease. ${ }^{44-46}$ However, it does not have a steroid-sparing effect. The European Crohn's and Colitis Organization consensus guidelines recommend use of sulfasalazine in patients with mildly active colonic Crohn's disease. ${ }^{46,47}$ It may also be appropriate in patients with associated arthropathy. ${ }^{47}$ Effective adult doses range from 4-6 gm per day (40-75 mg/kg/day in children). ${ }^{48}$ The sulfapyridine component of sulfasalazine has been implicated in many of its side effects, including allergic reactions, ${ }^{49,50}$ and efforts have been directed toward producing an effective 5-ASAbased drug which lacks sulfapyridine and is formulated in such a manner as to maximize delivery to the inflamed tissue - either colon or terminal ileum.

Delivery systems include enemas or suppositories, which provide the drug to the rectum and left colon; coating with protective materials that release the drug in a $\mathrm{pH}$-dependent manner to achieve controlled (Pentasa, Ferring Pharmaceuticals, Pymble, NSW, Australia) or delayed (Asacol, Warner Chilcott, Rockaway, NJ, USA) delivery, and diazo-bonding the drug to a second 5-ASA molecule (olsalazine) or to an inert carrier (balsalazide). Release profiles of the oral drugs vary depending on the coating preparation. Mesalamine delayed release (Asacol) has a Eudragit-S coating which releases at a $\mathrm{pH}$ of 7 or above, hence delivering the drug to the terminal ileum and distally. ${ }^{51}$ Salofalk (Orphan Australia, Dandenong, VIC, Australia), and Mesasal (Aspen Pharmacare, St Leonards, NSW, Australia) have a Eudragit L coating which releases at a $\mathrm{pH}$ of 6 or above and also delivers the drug to the terminal ileum. Controlled-release mesalamine capsules (Pentasa) have 
ethylcellulose-coated microgranules, releasing approximately half the dose in the duodenum, jejunum, and ileum, with the other half in the colon. Diazo-bonded preparations have release profiles closely resembling that of sulfasalazine..$^{52-54}$

However, there is conflicting evidence for mesalamine in inducing remission, and the role of the 5-ASA-derived drugs in Crohn's disease is still being established. One study has shown efficacy. ${ }^{55} \mathrm{~A}$ minimum daily dose of $4 \mathrm{gm}$ in adults was associated with a $43 \%$ remission rate in adults, compared to $18 \%$ for placebo. Moreover, there was some suggestion that it conferred additional benefit in patients with ileal disease, a benefit over sulfasalazine. However, subsequent trials have failed to show clinically significant benefit for Pentasa $4 \mathrm{gm}$ a day in inducing remission in patients with mild to moderate Crohn's disease,${ }^{56}$ or any clinically significant value in the prevention of relapse. ${ }^{57}$

5-ASA drugs remain frequently used in Crohn's disease. Side effects of sulfasalazine include fever, rash, hemolytic anemia, hepatitis, pancreatitis, headache, nausea, malaise, and anorexia. ${ }^{49,50}$ Newer ASA preparations are generally considered safer than sulfasalazine, but nevertheless are associated with adverse effects. Mesalamine has been reported to cause diarrhea, nephrotoxicity at an average rate of $0.26 \%$ per patient year and pancreatitis seven times more frequently than sulfasalazine. ${ }^{49,58,59}$ It can also rarely but dramatically affect the lungs, most likely through an allergic reaction, causing eosinophilic pneumonia, bronchiolitis obliterans, pleural effusion, or pulmonary fibrosis. ${ }^{42,50,59,60}$

Mesalamine has been reported to be safe and effective in children and adolescents in the limited data that is available. ${ }^{61}$ However, it has not been shown to be effective in maintaining remission in a double-blind, multicenter, randomized, placebo-controlled trial. ${ }^{62}$

A Cochrane meta-analysis on the efficacy of aminosalicylates concluded that sulfasalazine has modest efficacy compared to placebo but is inferior to steroids in the treatment of mild to moderate Crohn's disease. ${ }^{63}$ High-dose mesalamine was reported to be inferior to budesonide and not more effective than placebo for inducing remission. ${ }^{63}$

\section{Corticosteroids}

Corticosteroids, usually prednisolone and its equivalents, are frequently used as first-line agents to induce remission in moderate to severe Crohn's disease. ${ }^{38,64}$ Systemic corticosteroids achieve response rates of up to $90 \%$ for active disease in most distributions. ${ }^{44}$ Typically, steroids are administered as a pulse and tapered over weeks to months, depending on clinical response. There is no evidence that any one tapering regimen is better than another. ${ }^{64}$ Recurrent symptoms on tapering or shortly after cessation are termed steroid dependency; this is fairly common, occurring in about a third of patients. ${ }^{64}$ Steroid resistance, which can develop over time in about $40 \%$ of patients, can result from a range of molecular mechanisms. ${ }^{64,65}$

The concern with the use of systemic corticosteroids lies in the increased risks for infection, growth, and skeletal health ${ }^{66,67}$ although their impact on bone health may not be as much as was once thought. ${ }^{68,69}$ Steroid-naïve newly diagnosed patients have lower bone density than healthy controls, ${ }^{70}$ and so it would appear that uncontrolled IBD itself is likely to have the most important impact on bone health in current treatment regimens. Toxicity relates to dose and duration. Mood swings, acne, and Cushingoid facies can be very difficult for the adolescent patient in particular.

Budesonide is a corticosteroid with extensive first-pass metabolism (85\%) and low systemic bioavailability. Targeted delivery to the ileum and the right colon is achieved through specific $\mathrm{pH}$ and time-dependent formulation. Clinical efficacy is nearly the same as prednisolone in adults, ${ }^{71}$ which is also the case for children with Crohn's disease. ${ }^{72}$ The potential advantage of budesonide with particular relevance to pediatric practice is that it is associated with significantly fewer side effects and less adrenal suppression than prednisolone. ${ }^{73}$ However, neither drug decreases the risk of relapse during maintenance therapy, ${ }^{44,74}$ and so should not form part of longterm therapy.

\section{Exclusive enteral nutrition}

Exclusive enteral nutrition (EEN) refers to the exclusive use of either an elemental or polymeric liquid formula for 6-8 weeks to induce remission in Crohn's disease. ${ }^{75}$ Normal diet is slowly reintroduced after the 8 -week period. ${ }^{76}$ Despite its low risk and relatively high efficacy, it is relatively underused except in pediatric practice in some countries, and in Japan in both adults and children. ${ }^{77}$ Multiple studies have shown EEN to be a safe and effective agent for inducing remission in active Crohn's disease without the side effects of corticosteroids..$^{75,78-80}$ There is evidence, for instance, that EEN may provide for better skeletal health outcomes compared to steroid-induced remission. ${ }^{81}$ Mucosal healing rates are substantially better than for corticosteroids, ${ }^{75,81,82}$ although there is controversy as to whether clinical response rates are equivalent, worse, or better than with steroids. ${ }^{75,77,83}$

Enteral feeds appear to be effective in maintaining remission, either alone or alternating with normal feeds, as partial EEN or combined with conventional pharmacotherapy. ${ }^{75,84}$ 
Notwithstanding the advantages of EEN, its uptake has been extremely limited with wide variability worldwide in its use as a first-line therapy, ranging from $62 \%$ among European pediatric gastroenterologists to only 4\% of North American gastroenterologists. ${ }^{75,85}$ Likely reasons include lack of experience among treating physicians, perceptions of poor acceptability, lack of dietetic support, and difficulty in organizing feeds comparing to prescribing conventional pharmacotherapy. ${ }^{75}$ The feeds are of limited palatability, monotonous, and may require an enteral tube, and patients crave the sensation of eating. ${ }^{76,86}$

\section{Immunomodulators}

Immunomodulators are another group of drugs used in the management of moderate to severe Crohn's disease both for induction and in maintenance therapy. ${ }^{87}$ They were initially used in the treatment of steroid-dependent or -resistant Crohn's disease, but now are increasingly used as a primary adjunctive therapy in more severe disease, especially in children. ${ }^{88}$ The thiopurines azathioprine and 6-mercaptopurine are the most widely used, with increasing use of methotrexate. Azathioprine is converted nonenzymatically into 6-mercaptopurine. ${ }^{89}$

Neither azathioprine nor 6-mercaptopurine are very effective as single agents for induction, but when added to corticosteroids at first commencement of therapy were associated with lower cumulative corticosteroid dose and prolonged remission in a double-blind, placebo-controlled study in children. ${ }^{39}$ There is relatively little evidence regarding methotrexate as a similar adjunctive agent in inducing a remission, but prevailing guidelines suggest that it is probably as effective as thiopurines in this situation. ${ }^{40}$

Both azathioprine and 6-mercaptopurine effectively maintain remission. Studies have shown that there is a clear benefit of continuing azathioprine or 6-mercaptopurine for at least 18 months to maintain remission. ${ }^{90}$ Methotrexate is also effective for maintenance therapy and tends to be used in patients resistant to or intolerant to thiopurines. ${ }^{91}$ There is limited data on the safety and efficacy in children, but available studies suggest that methotrexate is a safe and effective alternative to thiopurines in maintaining remission. ${ }^{92,93}$ Methotrexate is usually given by a parenteral route, either subcutaneous or intramuscular, to patients with Crohn's disease, but there is some evidence that the bioavailability of orally administered methotrexate may be only slightly less than parenteral and a small dose adjustment may enable the drug to be given orally with similar clinical efficacy. ${ }^{94}$ Methotrexate has been implicated in hypersensitivity pneumonitis $(0.3 \%)$, nausea, and rash. The risk of hepatic fibrosis is thought to be low in patients with IBD treated with methotrexate.

The metabolism of thiopurines is moderately complex but of importance clinically. The therapeutically active metabolite is 6-thioguanine. A rare mutation resulting in impaired activity of the enzyme thiopurine methyl transferase (TPMT) may lead to raised 6-thioguanine levels with consequent toxicity, including myelosuppression. TPMT activity or the genotype should be measured before commencing full-dose therapy with azathioprine or 6-mercaptopurine. ${ }^{95}$ Thiopurines may still be used, but the dose should be reduced to $9 \%-28 \%$. This cohort of patients often experiences clinical response despite the relatively lower doses of the drug. ${ }^{89}$ Variation in the metabolism of thiopurines separately also warrants measurements of metabolites, which can be used to optimize dosing. ${ }^{95}$ Under- and overdosing can be identified, as well as nonadherence and shunting, which may be amenable to manipulation by dose adjustment and coadministration of allopurinol. ${ }^{96}$

\section{Biologicals}

Although the primary cause of Crohn's disease remains poorly understood, it is recognized to represent a process of unopposed inflammation in the gut. A number of endogenously produced biologically active molecules mediate this inflammation. Biologics represent a class of drugs which specifically target molecules and pathways central to the inflammatory process. Infliximab, the first of these to become available, is a monoclonal antibody directed against tumor necrosis factor-alpha (TNF- $\alpha$ ), a major proinflammatory cytokine in both Crohn's disease and ulcerative colitis. TNF- $\alpha$ is released from macrophages, monocytes, and T-cell lymphocytes (most likely CD4+ cells) in response to various stimuli, including bacterial endotoxins, viral antigens, and radiation. It is also believed to be pivotal in granuloma formation. ${ }^{97}$

Infliximab has dramatically transformed the treatment paradigm in IBD. ${ }^{98}$ It has been used both to induce remission and as a maintenance agent. There is long-standing experience with it in both adults and children. Adalimumab and certolizumab are also monoclonal antibodies directed against TNF- $\alpha$, but there is less experience with these agents in children and access to both varies from country to country. Other agents directed against a range of molecular targets are undergoing development and evaluation.

Trial data has established the efficacy of infliximab, adalimumab, and certolizumab in inducing response in adult patients with moderate to severe luminal disease. ${ }^{99-101}$ Similar or better results have been established for infliximab 
and adalimumab in children. ${ }^{102,103}$ Short-term response rates vary from $50 \%-80 \%$, with endoscopic healing in a substantial proportion. The ACCENT (A Crohn's Disease Clinical Trial Evaluating Infliximab in a New Long-Term Treatment Regimen) trial established that a single infusion of $5 \mathrm{mg} / \mathrm{kg}$ infliximab produced a clinical response in 58\% of adult patients with moderate to severe Crohn's disease. ${ }^{104}$ Infliximab is also effective in healing fistulizing disease, and for extraintestinal complications of Crohn's disease such as pyoderma gangrenosum. ${ }^{105}$

The biologics are also effective maintenance agents. Regular scheduled treatments with either infliximab (every 8 weeks) or adalimumab (every 2 weeks) are effective in maintaining remission in both luminal Crohn's disease and fistulae. The ACCENT trial in adults found that $42 \%$ of adult patients receiving regular scheduled infliximab every 8 weeks were still in remission 7 months later. ${ }^{104}$ Experience with duration of efficacy in children has been better, with maintenance of remission varying from 56\%-93\% after 54 weeks. ${ }^{102,106}$ Long-term duration of response in children has been reported to vary from $67 \%-72 \%$ at 3 years.

Maintenance of clinical response with long-term biological therapy in children is accompanied by normal growth, progression through puberty, and optimized skeletal health, as well as the resolution of symptoms that can have a profound impact on quality of life and psychosexual well-being and development. ${ }^{107-110}$ Loss of response to the biological can represent a disaster for any patient, but particularly for a growing and maturing child or adolescent. It is believed that the most likely cause of secondary loss of response is the development of antibodies to the biologic agent. Concomitant therapy with an immunosuppressant appears likely to reduce the chances of antibody development, ${ }^{111-113}$ but this practice has been complicated by the recognition of the potential increased risk of development of malignancy, especially hepatosplenic T-cell lymphoma (HSTCL). HSTCL is a rare and usually fatal lymphoma reported in association with past use of thiopurines, either alone or in combination with infliximab or adalimumab. ${ }^{114-116}$ It has occurred primarily in young males. Explaining and balancing the relative risks of an extremely rare but fatal complication with that of a much more likely serious morbidity can be extremely challenging, and invariably management will be individualized depending on many factors. ${ }^{117,118}$

Although biologics are generally well tolerated, they do have to be administered parenterally - in the case of infliximab, by infusions every 8 weeks, and for adalimumab, by subcutaneous injection every 2 weeks. Potential adverse effects usually relate to infusion reactions, opportunistic infections, dermatological conditions, or malignancy. ${ }^{98,116}$

Immediate hypersensitivity reaction to infliximab infusion presenting as hypotension, headache, and pruritus has been reported in $15 \%$ patients in various studies. ${ }^{119,120}$ Female gender and short duration of immunomodulator use have been reported to be risk factors for a reaction. ${ }^{116,121,122}$ However, desensitization by gradual incremental re-exposure to infliximab has been shown to be effective. ${ }^{116,122,123}$ Approximately $6 \%$ of patients are reported to have delayed hypersensitivity reactions presenting as polyarthralgia or fever. ${ }^{124}$ Delayed hypersensitivity reactions are believed to be more common in adults with a significant interval between doses, but the same has not been reported in children. ${ }^{119,124}$

Treatment with infliximab is often associated with an increase in titer of antinuclear antibodies but the development of antidouble-stranded DNA is uncommon. ${ }^{125}$ Lupus is a well-recognized, albeit rare, development, but it usually responds well to modification of biologic therapy. ${ }^{126}$ There have also been case reports of psoriasis induced by infliximab therapy, with up to $10 \%$ of pediatric patients developing new-onset psoriasis. ${ }^{127}$ There is a suspected link between polymorphisms in the IL-23R gene and the development of psoriasis in this situation. ${ }^{127}$

Severe infections are also known to occur more frequently in patients on anti-TNF- $\alpha$ agents, ${ }^{128}$ but the risks contributed by concurrent presence of moderate to severe Crohn's disease, use of narcotic analgesics, and steroid therapy are proportionately greater. There is also no evidence from the Crohn's Therapy Resource, Evaluation and Assessment Tool registry of an increased risk of mortality with infliximab therapy. ${ }^{128}$ In the REACH (A Randomized, multicenter, open-label study to Evaluate the safety and efficacy of Anti-TNF- $\alpha$ Chimeric monoclonal antibody in pediatric subjects with moderate to severe Crohn's disease) study, nearly $8 \%$ of children developed a serious infection. ${ }^{102}$ The greatest risks are for opportunistic infections or reactivation of latent infections. ${ }^{16,129}$ It is extremely important to screen the patient for possible evidence of latent chronic infections such as tuberculosis and hepatitis B or C before embarking on anti-TNF- $\alpha$ therapy, but even more important to appropriately manage any infections that develop in the immunosuppressed patient using established guidelines. ${ }^{130}$

\section{Other therapeutic options}

Despite the advances in pharmacotherapy in the last few decades, no current drug is either ideal or curative. Other therapeutic options that have been pursued with variable success 
include antibiotics, probiotics, nutritional supplementation, drugs for symptomatic relief (such as antidiarrheals), and of course surgery. In the absence of success with mainstream medical approaches, many patients pursue alternative medical therapies.

\section{Emerging trends}

We have come a long way in our understanding of Crohn's disease since it was first described in 1932. The last decade has been a period of rapid discoveries, especially in the field of metagenomics. It has been common knowledge that the human gut harbors a large number of commensal microorganisms. However, their role in causing or preventing illnesses has only been a matter of speculation until recently. There is now increasing evidence that imbalance in the gut microbiota, dysbiosis, could be implicated in the pathogenesis of Crohn's disease. Further research is now targeted to try and find the exact mechanism of causation of Crohn's disease. Recent research has also shown that bacteriophages may also be implicated in the pathogenesis of Crohn's disease. Expanding our knowledge of the role of microbiota will allow better and more personalized management of Crohn's disease.

Advances in microbiological and immunological analytical techniques have allowed us to target specific proteins at a molecular level. Drugs are being trialled that target specific inflammatory molecules. ABT 874 (J695), a human immunoglobulin (IgG1) monoclonal antibody to interleukin12/23, was found to induce clinical remission in patients with active Crohn's disease. ${ }^{131}$ Since then, ustekinumab, another humanized monoclonal antibody against the p40 subunit of interleukins $12 / 23$, has been found to have clinical efficacy in adults with Crohn's disease. ${ }^{131}$ There are no reports on its use in pediatric population. Similarly, CCX282-B (a chemokine receptor 9 antagonist), MLN 0002 (an anti- $\alpha 4 \beta 7$ antibody), ruMab $\beta-7$ (an anti- $\beta 7$ antibody), CP-690, 550 (an antagonist to janus kinase 3), AIN476 (an anti-IL-7 antibody), and basiliximab (Simulect ${ }^{\circledR}$, Novartis Pharmaceuticals, Basel, Basel-Stadt, Switzerland; an anti-IL-2 receptor [CD25]) antibody are all undergoing trials as potential therapies in Crohn's disease. ${ }^{132}$ Further longitudinal studies are required to establish their safety over prolonged use. Further research is now directed towards finding more effective and safer modalities of treatment and possibly a cure.

Extracorporeal photopheresis (ECP) has been on the horizon for almost a decade and has been successfully used for treatment of various T-cell-mediated conditions, including advanced T-cell lymphoma, systemic sclerosis, graft-versus-host disease, and prevention and treatment of solid organ transplant rejection. ${ }^{133}$ It was first trialled in Crohn's disease in 2001; recently, there has been a renewed interest in its use in steroid-dependent Crohn's disease. It involves exposure of autologous peripheral blood mononuclear cells to 8-methoxypsoralen and long wavelength ultraviolet-A light followed by reinfusion into the patient. Animal studies suggest that the photopheresed cells induce an antigen-specific immune response directed to pathogenic T-cells while sparing general immunocompetence. ${ }^{134}$ ECP was shown to have a steroid-sparing effect in adults with steroid-dependent Crohn's disease in a prospective, singlecenter study in 2001. ${ }^{135}$ A multicenter prospective trial has shown that ECP permitted discontinuation or reduction in steroid doses in steroid-dependent adult Crohn's disease patients. ${ }^{134}$ There is limited pediatric data on the safety and efficacy of ECP. Recently, a case of a 12-year-old patient with severe, unremitting Crohn's disease was reported who responded favorably to ECP. ${ }^{136}$ However, prospective long-term studies are needed in children to conclusively demonstrate its efficacy and safety.

\section{Growth and bone health}

Impaired growth is a major concern for families and children affected by Crohn's disease. It has both physical and psychosocial implications. Children are not infrequently growthimpaired at diagnosis, but improvements in therapies have allowed a better long-term outcome, with most children going on to achieve an adult height within the normal range. ${ }^{137-139}$ About $20 \%$ of children will still fail to achieve normal growth expectations; late diagnosis and jejunal disease are predictive of long-term growth impairment. ${ }^{139}$

With optimization of growth in mind, there are three important aims to follow in management: 1) control disease activity, 2) optimize nutrition, and 3) minimize the use of corticosteroids (but not at the expense of poor disease control). ${ }^{137,140,141}$ Disease activity has the strongest influence on growth failure, with smaller nutritional and iatrogenic components. ${ }^{137}$ This inhibition appears to be mediated through inflammatory cytokines, ${ }^{142}$ with a knock-on impact on pubertal development. Several different growth impairment phenotypes have been identified, including growth hormone and insulin-like growth factor-1 (IGF1) deficiency states. ${ }^{143}$ Therapeutic targets can be difficult to identify. Interleukin- 6 and TNF- $\alpha$ have been implicated in the suppression of the growth hormone axis by inhibiting hepatocyte IGF1 production. ${ }^{144,145}$ Interleukin-1 and TNF- $\alpha$ both inhibit activity at the growth plate in long bones in vitro. ${ }^{146}$

Given the importance of TNF- $\alpha$ in growth retardation, the specifically targeted action of anti-TNF- $\alpha$ agents may have 
a disproportionately beneficial impact on growth compared to standard therapies. ${ }^{116}$ The REACH study found a mean improvement in $z$-score for height of $0.5(P<0.001)$ after 54 week therapy with infliximab. ${ }^{102}$ The limitation of this finding was the failure to control for pubertal status. ${ }^{147}$ Subsequent studies have provided more compelling evidence of infliximab's efficacy in growth. Walters et al ${ }^{148}$ established the importance of appropriately early timing of treatment; height and height velocities were most improved when (infliximab) therapy was initiated before or during early puberty (Tanner I-III). The heterogeneity of growth impairment was supported by a study of 28 children who were retrospectively assessed over an 18-month period, during which time all received induction therapy with infliximab, with some also receiving maintenance therapy. ${ }^{149}$ Patients who responded to infliximab (75\%) had a mean improvement in height velocity of $4.4 \mathrm{~cm} /$ year compared to nonresponders whose height velocity remained static. Although many progressed into puberty during the study, children who remained prepubertal also had improvements in growth. The implication was that growth improved independent of any permissive effect infliximab had on pubertal progression. There is also evidence that increasing infliximab dosing frequency may further improve growth. ${ }^{150}$

Skeletal health can also be impaired in Crohn's disease. ${ }^{66}$ Treatment with infliximab can result in dramatic improvements in biomarkers of bone formation, ${ }^{151}$ as might be expected given the known inhibitory effects of TNF- $\alpha$ on osteoblast differentiation, osteoblast collagen secretion, and induction of osteoblast apoptosis. ${ }^{152,153}$ A similar beneficial effect on growth has also been established for adalimumab. ${ }^{109}$

\section{Psychosocial implications}

Crohn's disease is a lifelong disease with no cure and a substantial psychosocial burden. Studies have reported a higher lifetime risk of depressive disorders in patients with IBD compared to cystic fibrosis patients. ${ }^{154,155} \mathrm{~A}$ few other studies have shown a higher incidence of depression and anxiety-related disorders in patients with IBD compared to healthy children but similar to children with other chronic illnesses. ${ }^{155-157}$ Studies of the effect of steroids on mood disorders have shown that patients on steroids had significantly more problems with verbal memory, working memory, and depression compared to patients not on steroids. ${ }^{155}$

Crohn's disease in particular also has a significant impact on social functioning in patients, especially those diagnosed in adolescence. ${ }^{155,158}$ Children with IBD have been shown to have fewer close friends and participate in fewer organized leisure activities as compared to healthy peers. ${ }^{155,159}$

Families of children with IBD also experience significant psychosocial problems. It has been shown that $51 \%$ of mothers of children with Crohn's disease had a lifetime history of depression and $10 \%$ had a current diagnosis of depression. ${ }^{160}$ These rates have been shown to be similar to those in families of cystic fibrosis patients. ${ }^{155,160}$

Studies have also shown that IBD adversely affects self-esteem. These patients also had poorer coping skills in stressful situations and were more likely to adopt avoidant coping styles. ${ }^{155,157,161}$

\section{Conclusion}

Crohn's disease is at present a lifelong, incurable condition with a substantial and ongoing impact on health, normal development, and psychosocial functioning. Despite significant improvements in our understanding and management of Crohn's disease, many unanswered questions remain. Most of these center around its pathogenesis, with tantalizing clues that may yet yield a cure. We are still unable to explain the increasing incidence and its spread to Asian and African nations. The relative importance and roles of environment, genetics, and dysbiosis are unknown. Can we prevent Crohn's disease by modifying our lifestyle or dietary habits? This remains to be answered.

Therapeutic interventions are at present limited to medications that inhibit the persistent inflammation without a real understanding of the trigger. The nature of symptoms and the disease process has a profound impact on the growing child and adolescent, but in general, better therapeutic control of the disease provides a much better outcome than unfettered inflammation.

\section{Disclosure}

The authors report no conflicts of interest in this work. Professor Catto-Smith has received speaker's fees from Janssen and honoraria as a member of advisory boards.

\section{References}

1. Crohn BB, Ginzburg L, Oppenheimer GD. Landmark article Oct 15, 1932. Regional ileitis. A pathological and clinical entity. By Burril B Crohn, Leon Ginzburg, and Gordon D Oppenheimer. JAMA. 1984;251(1):73-79.

2. Phavichitr N, Cameron DJ, Catto-Smith AG. Increasing incidence of Crohn's disease in Victorian children. $J$ Gastroenterol Hepatol. 2003;18(3):329-332.

3. Molodecky NA, Soon IS, Rabi DM, et al. Increasing incidence and prevalence of the inflammatory bowel diseases with time, based on systematic review. Gastroenterology. 2012;142(1):46-54.e42; quiz e30. 
4. Pant C, Anderson MP, Deshpande A, et al. Trends in hospitalizations of children with inflammatory bowel disease within the United States from 2000 to 2009. J Investig Med. 2013;61(6):1036-1038.

5. Benchimol EI, Fortinsky KJ, Gozdyra P, Van den Heuvel M, Van Limbergen J, Griffiths AM. Epidemiology of pediatric inflammatory bowel disease: a systematic review of international trends. Inflamm Bowel Dis. 2011;17(1):423-439.

6. Cosnes J, Gower-Rousseau C, Seksik P, Cortot A. Epidemiology and natural history of inflammatory bowel diseases. Gastroenterology. 2011;140(6):1785-1794.

7. Wilson J, Hair C, Knight R, et al. High incidence of inflammatory bowel disease in Australia: a prospective population-based Australian incidence study. Inflamm Bowel Dis. 2010;16(9):1550-1556.

8. Sood A, Midha V, Sood N, Bhatia AS, Avasthi G. Incidence and prevalence of ulcerative colitis in Punjab, North India. Gut. 2003;52(11): $1587-1590$.

9. Bernstein CN. Assessing environmental risk factors affecting the inflammatory bowel diseases: a joint workshop of the Crohn's and Colitis Foundations of Canada and the USA. Inflamm Bowel Dis. 2008;14(8): 1139-1146.

10. Gearry RB, Richardson AK, Frampton CM, Dodgshun AJ, Barclay ML. Population-based cases control study of inflammatory bowel disease risk factors. J Gastroenterol Hepatol. 2010;25(2):325-333.

11. Ponsonby AL, Catto-Smith AG, Pezic A, et al. Association between early-life factors and risk of child-onset Crohn's disease among Victorian children born 1983-1998: a birth cohort study. Inflamm Bowel Dis. 2009;15(6):858-866.

12. Klement E, Lysy J, Hoshen M, Avitan M, Goldin E, Israeli E. Childhood hygiene is associated with the risk for inflammatory bowel disease: a population-based study. Am J Gastroenterol. 2008;103(7): 1775-1782.

13. Bernstein CN, Shanahan F. Disorders of a modern lifestyle: reconciling the epidemiology of inflammatory bowel diseases. Gut. 2008;57(9): 1185-1191.

14. Armitage E, Drummond HE, Wilson DC, Ghosh S. Increasing incidence of both juvenile-onset Crohn's disease and ulcerative colitis in Scotland. Eur J Gastroenterol Hepatol. 2001;13(12):1439-1447.

15. Wang XQ, Zhang Y, Xu CD, et al. Inflammatory bowel disease in Chinese children: a multicenter analysis over a decade from Shanghai. Inflamm Bowel Dis. 2013;19(2):423-428.

16. Ng SC, Tang W, Ching JY, et al; Asia-Pacific Crohn's and Colitis Epidemiologic Study (ACCESS) Study Group. Incidence and phenotype of inflammatory bowel disease based on results from the Asia-pacific Crohn's and colitis epidemiology study. Gastroenterology. 2013;145(1): 158-165. e2.

17. Xavier RJ, Podolsky DK. Unravelling the pathogenesis of inflammatory bowel disease. Nature. 2007;448(7152):427-434.

18. McGovern DP, Hysi P, Ahmad T, et al. Association between a complex insertion/deletion polymorphism in NOD1 (CARD4) and susceptibility to inflammatory bowel disease. Hum Mol Genet. 2005;14(10): 1245-1250.

19. Kufer TA, Banks DJ, Philpott DJ. Innate immune sensing of microbes by Nod proteins. Ann NY Acad Sci. 2006;1072:19-27.

20. Ponsky T, Hindle A, Sandler A. Inflammatory bowel disease in the pediatric patient. Surg Clin North Am. 2007;87(3):643-658.

21. Lesage S, Zouali H, Cézard JP, et al; EPWG-IBD Group; EPIMAD Group; GETAID Group. CARD15/NOD2 mutational analysis and genotype-phenotype correlation in 612 patients with inflammatory bowel disease. Am J Hum Genet. 2002;70(4):845-857.

22. Marcuzzi A, Bianco AM, Girardelli M, et al. Genetic and functional profiling of Crohn's disease: autophagy mechanism and susceptibility to infectious diseases. Biomed Res Int. 2013;2013:297501.

23. Ahmad T, Armuzzi A, Bunce M, et al. The molecular classification of the clinical manifestations of Crohn's disease. Gastroenterology. 2002;122(4):854-866.

24. Newman B, Siminovitch KA. Recent advances in the genetics of inflammatory bowel disease. Curr Opin Gastroenterol. 2005;21(4):401-407.
25. Kaakoush NO, Day AS, Huinao KD, et al. Microbial dysbiosis in pediatric patients with Crohn's disease. J Clin Microbiol. 2012;50(10): 3258-3266.

26. De Cruz P, Prideaux L, Wagner J, et al. Characterization of the gastrointestinal microbiota in health and inflammatory bowel disease. Inflamm Bowel Dis. 2012;18(2):372-390.

27. Prideaux L, Kang S, Wagner J, et al. Impact of ethnicity, geography, and disease on the microbiota in health and inflammatory bowel disease. Inflamm Bowel Dis. 2013;19(13):2906-2918.

28. Wagner J, Sim WH, Lee KJ, Kirkwood CD. Current knowledge and systematic review of viruses associated with Crohn's disease. Rev Med Virol. 2013;23(3):145-171.

29. Wagner J, Maksimovic J, Farries G, et al. Bacteriophages in gut samples from pediatric Crohn's disease patients: metagenomic analysis using 454 pyrosequencing. Inflamm Bowel Dis. 2013;19(8): 1598-1608.

30. Reyes A, Semenkovich NP, Whiteson K, Rohwer F, Gordon JI. Going viral: next-generation sequencing applied to phage populations in the human gut. Nat Rev Microbiol. 2012;10(9):607-617.

31. Mills S, Shanahan F, Stanton C, Hill C, Coffey A, Ross RP. Movers and shakers: influence of bacteriophages in shaping the mammalian gut microbiota. Gut Microbes. 2013;4(1):4-16.

32. Behr MA, Schurr E. Mycobacteria in Crohn's disease: a persistent hypothesis. Inflamm Bowel Dis. 2006;12(10):1000-1004.

33. Kirkwood CD, Wagner J, Boniface K, et al. Mycobacterium avium subspecies paratuberculosis in children with early-onset Crohn's disease. Inflamm Bowel Dis. 2009;15(11):1643-1655.

34. Rosenfeld G, Bressler B. Mycobacterium avium paratuberculosis and the etiology of Crohn's disease: a review of the controversy from the clinician's perspective. Can J Gastroenterol. 2010;24(10): 619-624.

35. Jostins L, Ripke S, Weersma RK, et al; International IBD Genetics Consortium (IIBDGC). Host-microbe interactions have shaped the genetic architecture of inflammatory bowel disease. Nature. 2012;491(7422):119-124.

36. Verdier J, Deroche L, Allez M, et al. Specific IgG response against Mycobacterium avium paratuberculosis in children and adults with Crohn's disease. PLoS One. 2013;8(5):e62780.

37. Rogler G. Top-down or step-up treatment in Crohn's disease? Dig Dis. 2013;31(1):83-90.

38. Mesker T, van Rheenen PF, Norbruis OF, et al. Pediatric Crohn's disease activity at diagnosis, its influence on pediatrician's prescribing behavior, and clinical outcome 5 years later. Inflamm Bowel Dis. 2009;15(11): 1670-1677.

39. Markowitz J, Grancher K, Kohn N, Lesser M, Daum F. A multicenter trial of 6-mercaptopurine and prednisone in children with newly diagnosed Crohn's disease. Gastroenterology. 2000;119(4):895-902.

40. Terdiman JP, Gruss CB, Heidelbaugh JJ, Sultan S, Falck-Ytter YT; AGA Institute Clinical Practice and Quality Management Committee. American Gastroenterological Association Institute guideline on the use of thiopurines, methotrexate, and anti-TNF- $\alpha$ biologic drugs for the induction and maintenance of remission in inflammatory Crohn's disease. Gastroenterology. 2013;145(6):1459-1463.

41. Niess JH, Klaus J, Stephani J, et al. NOD2 polymorphism predicts response to treatment in Crohn's disease - first steps to a personalized therapy. Dig Dis Sci. 2012;57(4):879-886.

42. Alskaf E, Aljoudeh A, Edenborough F. Mesalazine-induced lung fibrosis. BMJ Case Rep. 2013;2013.

43. Peppercorn MA, Goldman P. The role of intestinal bacteria in the metabolism of salicylazosulfapyridine. J Pharmacol Exp Ther. 1972;181(3):555-562.

44. Summers RW, Switz DM, Sessions JT Jr, et al. National Cooperative Crohn's Disease Study: results of drug treatment. Gastroenterology. 1979;77(4 Pt 2):847-869.

45. Van Hees PA, Van Lier HJ, Van Elteren PH, et al. Effect of sulphasalazine in patients with active Crohn's disease: a controlled double-blind study. Gut. 1981;22(5):404-409. 
46. Gionchetti P, Calabrese C, Tambasco R, et al. Role of conventional therapies in the era of biological treatment in Crohn's disease. World $J$ Gastroenterol. 2011;17(14):1797-1806.

47. Dignass A, Van Assche G, Lindsay JO, et al; European Crohn's and Colitis Organisation (ECCO). The second European evidence-based Consensus on the diagnosis and management of Crohn's disease: Current management. J Crohns Colitis. 2010;4(1):28-62.

48. Inflammatory bowel disease. etG complete. Melbourne: Therapeutic Guidelines limited; 2014. Available from: http://www.tg.org.au. Accessed May 9, 2014.

49. Actis GC, Pazienza P, Rosina F. Mesalamine for inflammatory bowel disease: recent reappraisals. Inflamm Allergy Drug Targets. 2008;7(1):1-5.

50. Stein RB, Hanauer SB. Comparative tolerability of treatments for inflammatory bowel disease. Drug Saf. 2000;23(5):429-448.

51. Levesque BG, Kane SV. Searching for the delta: 5-aminosalicylic acid therapy for Crohn's disease. Gastroenterol Hepatol (N Y). 2011;7(5): 295-301.

52. Sands BE, Siegel CA. Crohn's Disease. In: Feldman M, Friedman LS, Brandt LJ, editors. Sleisenger and Fordtran's Gastrointestinal and Liver Disease: Pathophysiology, Diagnosis, Management. 9th ed, Vol 2. Philadelphia, PA: Saunders. 2010;2010:1941-1973.

53. Sandborn WJ, Hanauer SB. Systematic review: the pharmacokinetic profiles of oral mesalazine formulations and mesalazine pro-drugs used in the management of ulcerative colitis. Aliment Pharmacol Ther. 2003;17(1):29-42.

54. Allgayer H, Ahnfelt NO, Kruis W, et al. Colonic N-acetylation of 5-aminosalicylic acid in inflammatory bowel disease. Gastroenterology. 1989;97(1):38-41.

55. Singleton JW, Hanauer SB, Gitnick GL, et al. Mesalamine capsules for the treatment of active Crohn's disease: results of a 16-week trial. Pentasa Crohn's Disease Study Group. Gastroenterology. 1993;104(5): 1293-1301.

56. Hanauer SB, Strömberg U. Oral Pentasa in the treatment of active Crohn's disease: A meta-analysis of double-blind, placebo-controlled trials. Clin Gastroenterol Hepatol. 2004;2(5):379-388.

57. Akobeng AK, Gardener E. Oral 5-aminosalicylic acid for maintenance of medically-induced remission in Crohn's Disease. Cochrane Database Syst Rev. 2005CD003715.

58. van Bodegraven AA, Mulder CJ. Indications for 5-aminosalicylate in inflammatory bowel disease: is the body of evidence complete? World J Gastroenterol. 2006;12(38):6115-6123.

59. Storch I, Sachar D, Katz S. Pulmonary manifestations of inflammatory bowel disease. Inflamm Bowel Dis. 2003;9(2):104-115.

60. Foster RA, Zander DS, Mergo PJ, Valentine JF. Mesalamine-related lung disease: clinical, radiographic, and pathologic manifestations. Inflamm Bowel Dis. 2003;9(5):308-315.

61. D'agata ID, Vanounou T, Seidman E. Mesalamine in pediatric inflammatory bowel disease: a 10-year experience. Inflamm Bowel Dis. 1996;2(4):229-235.

62. Cezard JP, Munck A, Mouterde O, et al. Prevention of relapse by mesalazine (Pentasa) in pediatric Crohn's disease: a multicenter, doubleblind, randomized, placebo-controlled trial. Gastroenterol Clin Biol. 2009;33(1 Pt 1):31-40.

63. Lim WC, Hanauer S. Aminosalicylates for induction of remission or response in Crohn's disease. Cochrane Database Syst Rev. 2010CD008870

64. Yang YX, Lichtenstein GR. Corticosteroids in Crohn's disease. Am J Gastroenterol. 2002;97(4):803-823.

65. Farrell RJ, Kelleher D. Glucocorticoid resistance in inflammatory bowel disease. J Endocrinol. 2003;178(3):339-346.

66. Wong SC, Catto-Smith AG, Zacharin M. Pathological fractures in paediatric patients with inflammatory bowel disease. Eur J Pediatr. 2014;173(2):141-151.

67. Sandborn WJ. Steroid-dependent Crohn's disease. Can J Gastroenterol Hepatol. 2000;14 Suppl C:17C-22C.

68. Walther F, Fusch C, Radke M, Beckert S, Findeisen A. Osteoporosis in pediatric patients suffering from chronic inflammatory bowel disease with and without steroid treatment. J Pediatr Gastroenterol Nutr. 2006;43(1):42-51
69. Cravo M, Guerreiro CS, dos Santos PM, et al. Risk factors for metabolic bone disease in Crohn's disease patients. Inflamm Bowel Dis. 2010;16(12):2117-2124

70. Sakellariou GT, Moschos J, Berberidis C, et al. Bone density in young males with recently diagnosed inflammatory bowel disease. Joint Bone Spine. 2006;73(6):725-728.

71. Rutgeerts $\mathrm{P}$, Löfberg R, Malchow H, et al. A comparison of budesonide with prednisolone for active Crohn's disease. $N$ Engl J Med. 1994;331(13):842-845.

72. Levine A, Weizman Z, Broide E, et al; Israeli Pediatric Gastroenterology Association Budesonide Study Group. A comparison of budesonide and prednisone for the treatment of active pediatric Crohn disease. J Pediatr Gastroenterol Nutr. 2003;36(2):248-252.

73. Escher JC; European Collaborative Research Group on Budesonide in Paediatric IBD. Budesonide versus prednisolone for the treatment of active Crohn's disease in children: a randomized, double-blind, controlled, multicentre trial. Eur J Gastroenterol Hepatol. 2004;16(1):47-54.

74. Benchimol EI, Seow CH, Otley AR, Steinhart AH. Budesonide for maintenance of remission in Crohn's disease. Cochrane Database Syst Rev. 2009CD002913.

75. Kansal S, Wagner J, Kirkwood CD, Catto-Smith AG. Enteral nutrition in crohn's disease: an underused therapy. Gastroenterol Res Pract. 2013;2013:482108.

76. Critch J, Day AS, Otley A, King-Moore C, Teitelbaum JE, Shashidhar H; NASPGHAN IBD Committee. Use of enteral nutrition for the control of intestinal inflammation in pediatric Crohn disease. $J$ Pediatr Gastroenterol Nutr. 2012;54(2):298-305.

77. Hiwatashi N. Enteral nutrition for Crohn's disease in Japan. Dis Colon Rectum. 1997;40(Suppl 10):S48-S53.

78. Ruuska T, Savilahti E, Mäki M, Ormälä T, Visakorpi JK. Exclusive whole protein enteral diet versus prednisolone in the treatment of acute Crohn's disease in children. J Pediatr Gastroenterol Nutr. 1994;19(2): 175-180.

79. Heuschkel RB. Enteral nutrition in children with Crohn's disease. J Pediatr Gastroenterol Nutr. 2000;31(5):575.

80. Schwab D, Raithel M, Hahn EG. [Enteral nutrition in acute Crohn disease]. Z Gastroenterol. 1998;36(11):983-995.

81. Soo J, Malik BA, Turner JM, et al. Use of exclusive enteral nutrition is just as effective as corticosteroids in newly diagnosed pediatric Crohn's disease. Dig Dis Sci. 2013;58(12):3584-3591.

82. Fell JM, Paintin M, Arnaud-Battandier F, et al. Mucosal healing and a fall in mucosal pro-inflammatory cytokine mRNA induced by a specific oral polymeric diet in paediatric Crohn's disease. Aliment Pharmacol Ther. 2000;14(3):281-289.

83. Zachos M, Tondeur M, Griffiths AM. Enteral nutritional therapy for induction of remission in Crohn's disease. Cochrane Database Syst Rev. 2007(1):CD000542.

84. Akobeng AK, Thomas AG. Enteral nutrition for maintenance of remission in Crohn's disease. Cochrane Database Syst Rev. 2007(3):CD005984.

85. Levine A, Milo T, Buller H, Markowitz J. Consensus and controversy in the management of pediatric Crohn disease: an international survey. J Pediatr Gastroenterol Nutr. 2003;36(4):464-469.

86. Whitten KE, Rogers P, Ooi CY, Day AS. International survey of enteral nutrition protocols used in children with Crohn's disease. J Dig Dis. 2012;13(2):107-112.

87. Sandborn WJ. A review of immune modifier therapy for inflammatory bowel disease: azathioprine, 6-mercaptopurine, cyclosporine, and methotrexate. Am J Gastroenterol. 1996;91(3):423-433.

88. Riello L, Talbotec C, Garnier-Lengliné H, et al. Tolerance and efficacy of azathioprine in pediatric Crohn's disease. Inflamm Bowel Dis. 2011;17(10):2138-2143.

89. Kim MJ, Choe YH. Monitoring and safety of azathioprine therapy in inflammatory bowel disease. Pediatr Gastroenterol Hepatol Nutr. 2013;16(2):65-70.

90. French H, Mark Dalzell A, Srinivasan R, El-Matary W. Relapse rate following azathioprine withdrawal in maintaining remission for Crohn's disease: a meta-analysis. Dig Dis Sci. 2011;56(7):1929-1936. 
91. Feagan BG, Rochon J, Fedorak RN, et al. Methotrexate for the treatment of Crohn's disease. The North American Crohn's Study Group Investigators. N Engl J Med. 1995;332(5):292-297.

92. Boyle B, Mackner L, Ross C, Moses J, Kumar S, Crandall W. A single-center experience with methotrexate after thiopurine therapy in pediatric Crohn disease. J Pediatr Gastroenterol Nutr. 2010;51(6): 714-717.

93. Weiss B, Lerner A, Shapiro R, et al. Methotrexate treatment in pediatric Crohn disease patients intolerant or resistant to purine analogues. J Pediatr Gastroenterol Nutr. 2009;48(5):526-530.

94. Wilson A, Patel V, Chande N, et al. Pharmacokinetic profiles for oral and subcutaneous methotrexate in patients with Crohn's disease. Aliment Pharmacol Ther. 2013;37(3):340-345.

95. Sheffield LJ, Irving P, Gupta A, et al. Thiopurine methyltransferase and thiopurine metabolite testing in patients with inflammatory bowel disease who are taking thiopurine drugs. Pharmacogenomics. 2009;10(7):1091-1099.

96. van Asseldonk DP, Sanderson J, de Boer NK, et al; Thiopurine Task Force Interest Group. Difficulties and possibilities with thiopurine therapy in inflammatory bowel disease - proceedings of the first Thiopurine Task Force meeting. Dig Liver Dis. 2011;43(4): 270-276.

97. Parashette KR, Makam RC, Cuffari C. Infliximab therapy in pediatric Crohn's disease: a review. Clin Exp Gastroenterol. 2010;3:57-63.

98. Yang LS, Alex G, Catto-Smith AG. The use of biologic agents in pediatric inflammatory bowel disease. Curr Opin Pediatr. 2012;24(5): 609-614.

99. Hanauer SB, Sandborn WJ, Rutgeerts P, et al. Human anti-tumor necrosis factor monoclonal antibody (adalimumab) in Crohn's disease: the CLASSIC-I trial. Gastroenterology. 2006;130(2):323-333; quiz 591.

100. Sandborn WJ, Feagan BG, Stoinov S, et al. Certolizumab pegol for the treatment of Crohn's disease. N Engl J Med. 2007;357(3): $228-238$.

101. Targan SR, Hanauer SB, van Deventer SJ, et al. A short-term study of chimeric monoclonal antibody cA2 to tumor necrosis factor alpha for Crohn's disease. Crohn's Disease cA2 Study Group. N Engl J Med. 1997;337(15):1029-1035.

102. Hyams J, Crandall W, Kugathasan S, et al; REACH Study Group. Induction and maintenance infliximab therapy for the treatment of moderate-to-severe Crohn's disease in children. Gastroenterology. 2007;132(3):863-873; quiz 1165.

103. Rosh JR, Lerer T, Markowitz J, et al. Retrospective Evaluation of the Safety and Effect of Adalimumab Therapy (RESEAT) in pediatric Crohn's disease. Am J Gastroenterol. 2009;104(12):3042-3049.

104. Hanauer SB, Feagan BG, Lichtenstein GR, et al; ACCENT I Study Group. Maintenance infliximab for Crohn's disease: the ACCENT I randomised trial. Lancet. 2002;359(9317):1541-1549.

105. Siemanowski B, Regueiro M. Efficacy of infliximab for extraintestinal manifestations of inflammatory bowel disease. Curr Treat Options Gastroenterol. 2007;10(3):178-184.

106. Hyams JS, Lerer T, Griffiths A, et al; Pediatric Inflammatory Bowel Disease Collaborative Research Group. Long-term outcome of maintenance infliximab therapy in children with Crohn's disease. Inflamm Bowel Dis. 2009;15(6):816-822.

107. Beattie RM. Symposium 6: Young people, artificial nutrition and transitional care: Nutrition, growth and puberty in children and adolescents with Crohn's disease. Proc Nutr Soc. 2010;69(1):174-177.

108. Heuschkel R, Salvestrini C, Beattie RM, Hildebrand H, Walters T, Griffiths A. Guidelines for the management of growth failure in childhood inflammatory bowel disease. Inflamm Bowel Dis. 2008;14(6): 839-849.

109. Malik S, Ahmed SF, Wilson ML, et al. The effects of anti-TNF- $\alpha$ treatment with adalimumab on growth in children with Crohn's disease (CD). J Crohns Colitis. 2012;6(3):337-344.

110. Szigethy E, McLafferty L, Goyal A. Inflammatory bowel disease. Child Adolesc Psychiatr Clin N Am. 2010;19(2):301-318.
111. Miele E, Markowitz JE, Mamula P, Baldassano RN. Human antichimeric antibody in children and young adults with inflammatory bowel disease receiving infliximab. J Pediatr Gastroenterol Nutr. 2004;38(5):502-508.

112. Vermeire S, Noman M, Van Assche G, Baert F, D’Haens G, Rutgeerts P. Effectiveness of concomitant immunosuppressive therapy in suppressing the formation of antibodies to infliximab in Crohn's disease. Gut. 2007;56(9):1226-1231.

113. Gouldthorpe O, Catto-Smith AG, Alex G, Simpson D. Loss of response to long-term infliximab therapy in children with Crohn's disease. Pharmaceuticals (Basel). 2013;6(10):1322-1334.

114. Rosh JR, Gross T, Mamula P, Griffiths A, Hyams J. Hepatosplenic T-cell lymphoma in adolescents and young adults with Crohn's disease: a cautionary tale? Inflamm Bowel Dis. 2007;13(8):1024-1030.

115. Cucchiara S, Escher JC, Hildebrand H, Amil-Dias J, Stronati L, Ruemmele FM. Pediatric inflammatory bowel diseases and the risk of lymphoma: should we revise our treatment strategies? J Pediatr Gastroenterol Nutr. 2009;48(3):257-267.

116. Gouldthorpe O, Catto-Smith AG, Alex G. Biologics in paediatric Crohn's disease. Gastroenterol Res Pract. 2011;2011:287574.

117. Melmed GY, Spiegel BM, Bressler B, et al. The appropriateness of concomitant immunomodulators with anti-tumor necrosis factor agents for Crohn's disease: one size does not fit all. Clin Gastroenterol Hepatol. 2010;8(8):655-659.

118. Siegel CA, Finlayson SR, Sands BE, Tosteson AN. Adverse events do not outweigh benefits of combination therapy for Crohn's disease in a decision analytic model. Clin Gastroenterol Hepatol. 2012;10(1):46-51.

119. Lamireau T, Cézard JP, Dabadie A, et al; French-Speaking Group for Pediatric Gastroenterology Nutrition. Efficacy and tolerance of infliximab in children and adolescents with Crohn's disease. Inflamm Bowel Dis. 2004;10(6):745-750.

120. Stephens MC, Shepanski MA, Mamula P, Markowitz JE, Brown KA, Baldassano RN. Safety and steroid-sparing experience using infliximab for Crohn's disease at a pediatric inflammatory bowel disease center. Am J Gastroenterol. 2003;98(1):104-111.

121. Crandall WV, Mackner LM. Infusion reactions to infliximab in children and adolescents: frequency, outcome and a predictive model. Aliment Pharmacol Ther. 2003;17(1):75-84.

122. Puchner TC, Kugathasan S, Kelly KJ, Binion DG. Successful desensitization and therapeutic use of infliximab in adult and pediatric Crohn's disease patients with prior anaphylactic reaction. Inflamm Bowel Dis. 2001;7(1):34-37.

123. Duburque C, Lelong J, Iacob R, et al. Successful induction of tolerance to infliximab in patients with Crohn's disease and prior severe infusion reactions. Aliment Pharmacol Ther. 2006;24(5):851-858.

124. Kugathasan S, Levy MB, Saeian K, et al. Infliximab retreatment in adults and children with Crohn's disease: risk factors for the development of delayed severe systemic reaction. Am J Gastroenterol. 2002;97(6):1408-1414.

125. Garcia-Planella E, Domènech E, Esteve-Comas M, et al. Development of antinuclear antibodies and its clinical impact in patients with Crohn's disease treated with chimeric monoclonal anti-TNFalpha antibodies (infliximab). Eur J Gastroenterol Hepatol. 2003;15(4):351-354.

126. Wetter DA, Davis MD. Lupus-like syndrome attributable to anti-tumor necrosis factor alpha therapy in 14 patients during an 8-year period at Mayo Clinic. Mayo Clin Proc. 2009;84(11):979-984.

127. Sherlock ME, Walters T, Tabbers MM, et al. Infliximab-induced psoriasis and psoriasiform skin lesions in pediatric Crohn disease and a potential association with IL-23 receptor polymorphisms. J Pediatr Gastroenterol Nutr. 2013;56(5):512-518.

128. Lichtenstein GR, Feagan BG, Cohen RD, et al. Serious infection and mortality in patients with Crohn's disease: more than 5 years of follow-up in the TREAT ${ }^{\mathrm{TM}}$ registry. Am J Gastroenterol. 2012;107(9): 1409-1422.

129. Toruner M, Loftus EV Jr, Harmsen WS, et al. Risk factors for opportunistic infections in patients with inflammatory bowel disease. Gastroenterology. 2008;134(4):929-936. 
130. Veereman-Wauters G, de Ridder L, Veres G, et al; ESPGHAN IBD Porto Group. Risk of infection and prevention in pediatric patients with IBD: ESPGHAN IBD Porto Group commentary. J Pediatr Gastroenterol Nutr. 2012;54(6):830-837.

131. Sandborn WJ, Feagan BG, Fedorak RN, et al; Ustekinumab Crohn's Disease Study Group. A randomized trial of Ustekinumab, a human interleukin-12/23 monoclonal antibody, in patients with moderate-tosevere Crohn's disease. Gastroenterology. 2008;135(4):1130-1141.

132. Sandborn WJ. Current directions in IBD therapy: what goals are feasible with biological modifiers? Gastroenterology. 2008;135(5):1442-1447.

133. Knobler R, Barr ML, Couriel DR, et al. Extracorporeal photopheresis: past, present, and future. J Am Acad Dermatol. 2009;61(4):652-665.

134. Reinisch W, Knobler R, Rutgeerts PJ, et al. Extracorporeal photopheresis (ECP) in patients with steroid-dependent Crohn's disease: an open-label, multicenter, prospective trial. Inflamm Bowel Dis. 2013;19(2):293-300.

135. Reinisch W, Nahavandi H, Santella R, et al. Extracorporeal photochemotherapy in patients with steroid-dependent Crohn's disease: a prospective pilot study. Aliment Pharmacol Ther. 2001;15(9): 1313-1322.

136. Cheerva A, Dillard R, Bertolone S. Extracorporeal photopheresis for the treatment of severe, refractory steroid dependent pediatric Crohn's Disease. J Clin Apher. 2013;28(5):381-386.

137. Motil KJ, Grand RJ, Davis-Kraft L, Ferlic LL, Smith EO. Growth failure in children with inflammatory bowel disease: a prospective study. Gastroenterology. 1993;105(3):681-691.

138. Sawczenko A, Sandhu BK. Presenting features of inflammatory bowel disease in Great Britain and Ireland. Arch Dis Child. 2003;88(11): 995-1000.

139. Sawczenko A, Ballinger AB, Savage MO, Sanderson IR. Clinical features affecting final adult height in patients with pediatric-onset Crohn's disease. Pediatrics. 2006;118(1):124-129.

140. Newby EA, Sawczenko A, Thomas AG, Wilson D. Interventions for growth failure in childhood Crohn's disease. Cochrane Database Syst Rev. 2005CD003873.

141. Bousvaros A. Use of immunomodulators and biologic therapies in children with inflammatory bowel disease. Expert Rev Clin Immunol. 2010;6(4):659-666.

142. MacRae VE, Wong SC, Farquharson C, Ahmed SF. Cytokine actions in growth disorders associated with pediatric chronic inflammatory diseases (review). Int J Mol Med. 2006;18(6):1011-1018.

143. Wong SC, Smyth A, McNeill E, et al. The growth hormone insulin-like growth factor 1 axis in children and adolescents with inflammatory bowel disease and growth retardation. Clin Endocrinol (Oxf). 2010;73(2):220-228.

144. DiFedele LM, He J, Bonkowski EL, et al. Tumor necrosis factor alpha blockade restores growth hormone signaling in murine colitis. Gastroenterology. 2005;128(5):1278-1291.

145. Ahmed TA, Buzzelli MD, Lang CH, et al. Interleukin-6 inhibits growth hormone-mediated gene expression in hepatocytes. Am J Physiol Gastrointest Liver Physiol. 2007;292(6):G1793-G1803.

146. MacRae VE, Farquharson C, Ahmed SF. The restricted potential for recovery of growth plate chondrogenesis and longitudinal bone growth following exposure to pro-inflammatory cytokines. $J$ Endocrinol. 2006;189(2):319-328.
147. Griffiths AM, Otley AR, Hyams J, et al. A review of activity indices and end points for clinical trials in children with Crohn's disease. Inflamm Bowel Dis. 2005;11(2):185-196.

148. Walters TD, Gilman AR, Griffiths AM. Linear growth improves during infliximab therapy in children with chronically active severe Crohn's disease. Inflamm Bowel Dis. 2007;13(4):424-430.

149. Malik S, Wong SC, Bishop J, et al. Improvement in growth of children with Crohn disease following anti-TNF- $\alpha$ therapy can be independent of pubertal progress and glucocorticoid reduction. J Pediatr Gastroenterol Nutr. 2011;52(1):31-37.

150. Sinitsky DM, Lemberg DA, Leach ST, Bohane TD, Jackson R, Day AS. Infliximab improves inflammation and anthropometric measures in pediatric Crohn's disease. $J$ Gastroenterol Hepatol. 2010;25(4):810-816.

151. Thayu M, Leonard MB, Hyams JS, et al; Reach Study Group. Improvement in biomarkers of bone formation during infliximab therapy in pediatric Crohn's disease: results of the REACH study. Clin Gastroenterol Hepatol. 2008;6(12):1378-1384

152. Gilbert L, He X, Farmer P, et al. Expression of the osteoblast differentiation factor RUNX2 (Cbfa1/AML3/Pebp2alpha A) is inhibited by tumor necrosis factor-alpha. $J$ Biol Chem. 2002;277(4):2695-2701.

153. Radeff JM, Nagy Z, Stern PH. Involvement of PKC-beta in PTH, TNF-alpha, and IL-1 beta effects on IL-6 promoter in osteoblastic cells and on PTH-stimulated bone resorption. Exp Cell Res. 2001;268(2):179-188.

154. Burke P, Meyer V, Kocoshis S, et al. Depression and anxiety in pediatric inflammatory bowel disease and cystic fibrosis. J Am Acad Child Adolesc Psychiatry. 1989;28(6):948-951.

155. Mackner LM, Crandall WV, Szigethy EM. Psychosocial functioning in pediatric inflammatory bowel disease. Inflamm Bowel Dis. 2006;12(3): 239-244.

156. Engström I. Family interaction and locus of control in children and adolescents with inflammatory bowel disease. JAm Acad Child Adolesc Psychiatry. 1991;30(6):913-920.

157. Engström I, Lindquist BL. Inflammatory bowel disease in children and adolescents: a somatic and psychiatric investigation. Acta Paediatr Scand. 1991;80(6-7):640-647.

158. Engström I. Parental distress and social interaction in families with children with inflammatory bowel disease. J Am Acad Child Adolesc Psychiatry. 1991;30(6):904-912.

159. Mrakotsky C, Forbes PW, Bernstein JH, et al. Acute cognitive and behavioral effects of systemic corticosteroids in children treated for inflammatory bowel disease. J Int Neuropsychol Soc. 2013;19(1): 96-109.

160. Burke PM, Kocoshis S, Neigut D, Sauer J, Chandra R, Orenstein D. Maternal psychiatric disorders in pediatric inflammatory bowel disease and cystic fibrosis. Child Psychiatry Hum Dev. 1994;25(1):45-52.

161. Raymer D, Weininger O, Hamilton JR. Psychological problems in children with abdominal pain. Lancet. 1984;1(8374):439-440.

162. Schildkraut V, Alex G, Cameron DJ, et al. Sixty-year study of incidence of childhood ulcerative colitis finds eleven-fold increase beginning in 1990s. Inflamm Bowel Dis. 2013;19(1):1-6.
Pediatric Health, Medicine and Therapeutics

\section{Publish your work in this journal}

Pediatric Health, Medicine and Therapeutics is an international, peerreviewed, open access journal publishing original research, reports, editorials, reviews and commentaries. All aspects of health maintenance preventative measures and disease treatment interventions are addressed within the journal. Practitioners from all disciplines are invited to submit

\section{Dovepress}

their work as well as healthcare researchers and patient support groups. The manuscript management system is completely online and includes a very quick and fair peer-review system. Visit http://www.dovepress.com/ testimonials.php to read real quotes from published authors 